\title{
Processing and Characterization of PMMA Nanofiber Reinforced Epoxy Composites
}

\author{
Salwan Al-Assafi ${ }^{*}$, Nils de Bruijn'², Ahmed M. Al-Jumaily ${ }^{1}$ \\ ${ }^{1}$ Institute of Biomedical Technologies, Auckland University of Technology, Auckland, New Zealand \\ ${ }^{2}$ Academie for Technology, Health and Environment, Avans University of Applied Sciences, Breda, \\ Netherlands \\ Email: :Salwan.alassafi@aut.ac.nz
}

Received 2 May 2016; accepted 13 June 2016; published 16 June 2016

Copyright (C) 2016 by authors and Scientific Research Publishing Inc. This work is licensed under the Creative Commons Attribution International License (CC BY). http://creativecommons.org/licenses/by/4.0/

(c) (7) Open Access

\begin{abstract}
Growing demand for high-performance materials is driving the development of composites with nano material reinforcement. The use of nano reinforcement can provide a distinct advantage due to high surface area of the material. There are still many challenges in achieving the full potential of nanocomposites. In this paper, we investigate the performance of epoxy nanocomposites reinforced with short polymethyl methacrylate (PMMA) nanofibers. PMMA nanofibers were chopped and mixed with the epoxy resin and then the mixture was poured into a mould. Samples were cut to an appropriate size after cure and mechanical testing was carried out. Tensile and flexural strength and modulus were evaluated for samples with various fiber volume fractions to determine changes in mechanical performance. Also Scanning Electron Microscopy was utilized to investigate fracture surface and fiber-matrix interface. Results indicated that mechanical performance dropped as volume fraction of fibers increased, namely poor fiber-matrix adhesion and presence of porosity resulted in deterioration in strength and modulus. Further research is required to develop fiber coating system to enhance performance of the nanocomposite by improving fiber-matrix adhesion and fiber wet-out.
\end{abstract}

\section{Keywords}

Nanocomposite, Nanofiber, Epoxy, Electrospinning, PMMA, Polymer, Composites

\section{Introduction}

There is a growing interest in using nanofibers as reinforcement for composites. The high surface area of nano-

*Corresponding author.

How to cite this paper: Al-Assafi, S., de Bruijn, N. and Al-Jumaily, A.M. (2016) Processing and Characterization of PMMA Nanofiber Reinforced Epoxy Composites. World Journal of Nano Science and Engineering, 6, 58-63.

http://dx.doi.org/10.4236/wjnse.2016.62007 
fibers coupled with good fiber-matrix bonding offers exceptional properties due to the high fiber-matrix interface area [1]. One of the common techniques to produce nanofibers is electrospinning [2]-[6]. This process is recognised as an efficient technique to produce nanofibers from polymer solutions or melts and it dates back to the early 1930s [2] [3]. In this technique, an electric field is used to produce an electrically charged jet of polymer solution or polymer melt flowing out of pendant or sessile droplet [4]. Electrical forces stretch and thin the jet as it flows away from the droplet producing nanofibers in the range of $100 \mathrm{~nm}$ or less. Many applications have been reported for electrospun fibers, such as drug delivery, filtration, energy generation, and other applications [5]. The focus of this study is on the use of nanofibers in the reinforcement of composites.

Several studies have been conducted on utilizing nanofibers in the reinforcement of composites [7]-[15]. Song Lin et al. investigated reinforcement of 2,2-bis-[4-(methacryloxypropoxy)-phenyl]-propane (Bis-GMA) dental resin system with PAN core-PMMA shell nanofiber fabric prepared by electrospinning method [12]. Strong adhesion was reported between the nanofibers and the matrix, and consequently the mechanical performance was significantly improved. Compared to neat resin, flexural strength, flexural modulus and work of fracture improved by $18.7 \%, 14.1 \%$ and $64.8 \%$ respectively, after adding $7.5 \mathrm{wt} \%$ PAN-PMMA nanofibers.

Alejandro J. Rodriguez et al. studied reinforcement of polymer composites using multiscale-reinforcement fabrics (MRFs) [8]. The MRFs were fabricated by electrophoretic deposition of carbon fibers on the surface of carbon fiber layers. Improvements of $12 \%$ in interlaminar shear strength and $13 \%$ in compressive strength were reported. It was observed that failure mechanism was a combination of matrix detachment from the surface of the fiber and matrix failure.

The use of short electrospun polymeric nanofibers as reinforcement for nanocomposites has also been investigated [10] [11]. Nylon-6 and polyimide electrospun nanofiber mats were cut and dispersed for nanocomposite films at various nanofiber weight fractions. Results showed an improvement of $185 \%$ in the elastic modulus after adding $3.5 \mathrm{wt} \%$ short nylon- 6 nanofibers to a matrix of thermoplastic urethane. This significant increase was attributed to strong nanofiber-matrix adhesion due to hydrogen bonding, however, lower improvement was reported when the nylon- 6 nanofibers were used to reinforce PMMA matrix due to poor nanofiber-matrix adhesion caused by absence of hydrogen bonding. Shaohua Jiang et al. showed that the use of short nanofibers could be more efficient than long nanofibers [11]. The addition of $2 \mathrm{wt} \%$ polyimide nanofibers to polyimide matrix helped in improving tensile strength and modulus by $53 \%$ and $87 \%$ respectively. However, to achieve performance similar to that for the $2 \mathrm{wt} \%$ nanofiber composites, $38 \mathrm{wt} \%$ of continuously long fibers were required. The superior performance of the short nanofiber was attributed to the improved dispersability of the short nanofibers in the matrix polymer.

In this study, the use of short electrospun PMMA nanofibers in reinforcing epoxy resin has been assessed. Flexural and tensile properties were determined for epoxy samples with various nanofiber weight fractions. Furthermore, scanning electron microscopy (SEM) was utilized to examine fracture surface of the nanocomposite samples.

\section{Experimental Protocol}

\subsection{Materials}

Electrospun PMMA nanofibers in mat form were supplied by Revolution Fibres Ltd, Auckland, New Zealand. Average diameter range for the nanofibers was $150 \mathrm{~nm}-200 \mathrm{~nm}$, and nanofiber deposition weight was $0.5-15$ $\mathrm{g} / \mathrm{m}^{2}$. The matrix system used for this study was R180 Bisphenol A epoxy resin and H180 amine hardener supplied by Nuplex Industries Ltd, Auckland, New Zealand.

\subsection{Sample Preparation}

The PMMA nanofiber mat was cut into $10 \mathrm{~mm} \times 10 \mathrm{~mm}$ squares and fibres were mixed manually with epoxy resin at fibre weight fractions of $0 \mathrm{wt} \%, 0.5 \mathrm{wt} \%, 2 \mathrm{wt} \%$ and 5 . The fibre-epoxy mix was then placed under vacuum for 24 hours to remove air bubbles. The hardener was added at 1:5 hardener to epoxy weight ratio and was mixed thoroughly. Following this, the mixture was poured into silicone moulds and was allowed to cure under vacuum at room temperature for 24 hours.

Cured samples were removed from moulds and cut using a rotating blade saw to sample size of $40 \mathrm{~mm} \times 4.5$ $\mathrm{mm} \times 4.5 \mathrm{~mm}$ for the 3-point bend test measurement. A rotating blade saw and a CNC machine were used to 
prepare samples for tensile strength test. Dimensions of the samples were $40 \mathrm{~mm}$ in length, $10 \mathrm{~mm}$ gage length, $2.5 \mathrm{~mm}$ width, and thickness of $4 \mathrm{~mm}$.

\subsection{Mechanical Testing}

Tensile and 3-point bend tests were carried out on a universal testing machine to evaluate performance of nanocomposites with various fibre weight fractions. Cross-head speed of $2.5 \mathrm{~mm} / \mathrm{min}$ was used for the tensile test and $0.5 \mathrm{~mm} / \mathrm{min}$ for the 3-point bend test. A span of $30 \mathrm{~mm}$ was used for the 3-point bend test.

\subsection{Data Analysis}

Data collected from the tensile and 3-point bend tests were analyzed using IBM SPSS Statistics 22. A One-way ANOVA with an alpha of 0.05 was used to compare data for Young's modulus, tensile strength and work of fracture (WOF) for samples with fiber content of $0 \mathrm{wt} \%, 0.5 \mathrm{wt} \%, 2 \mathrm{wt} \%$ and $5 \mathrm{wt} \%$. WOF values were calculated by measuring area under stress-strain curve for tensile tests.

\section{Results and Discussion}

Scanning electron microscope (SEM) Hitachi SU-70 FEG-SEM was utilized to evaluate nanofibers and nanocomposite fracture surfaces. Figure 1 shows an SEM micrograph of PMMA nanofibers used in this study prior to mixing with epoxy resin.

Young's modulus of elasticity and flexural modulus of all samples were determined from tensile and 3-point bend test results respectively. Figure 2(a) and Figure 2(b) illustrate Young's and flexural modulus results for the neat resin control sample and for samples with nanofiber content of $0.5 \mathrm{wt} \%, 2 \mathrm{wt} \%$, and $5 \mathrm{wt} \%$. Young's modulus results showed no noticeable change in modulus after adding PMMA nanofibers. Flexural modulus results, on the other hand, showed an initial drop in modulus for the $0.5 \mathrm{wt} \%$ nanofiber samples, followed by an increase in modulus for the $2 \mathrm{wt} \%$ and $5 \mathrm{wt} \%$ nanofiber samples.

Tensile and flexural strength results are illustrated in Figure 3. While there was no statistically significant difference between the samples with various nanofiber content in the case of flexural strength test, tensile strength results indicate a drop in tensile strength with increasing nanofiber content. Drops of 35\% and 33\% in tensile strength average values were recorded for $2 \mathrm{wt} \%$ and $5 \mathrm{wt} \%$ nanofiber content respectively. Similar results were achieved when measuring WOF for the various samples, as shown in Figure 4. Drops of $41 \%$ and $48 \%$ in average values for WOF were recorded for $2 \mathrm{wt} \%$ and $5 \mathrm{wt} \%$ nanofiber content respectively. Results achieved in this study were not in agreement with results reported in other studies that showed significant improvement in mechanical performance with the addition of nanofibers [10]-[12]. These studies attributed the improvement in mechanical performance to strong fiber/matrix adhesion. In order to assess fiber/matrix adhesion in our study, SEM was utilized to examine fracture surfaces to help determine cause in drop of tensile

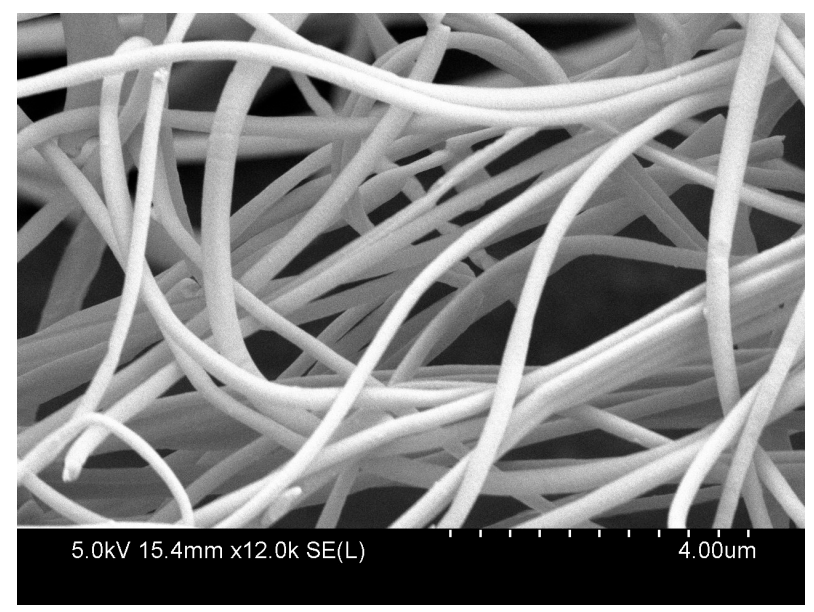

Figure 1. SEM micrograph of PMMA nanofibers at a magnification of $12 \mathrm{k}$. 


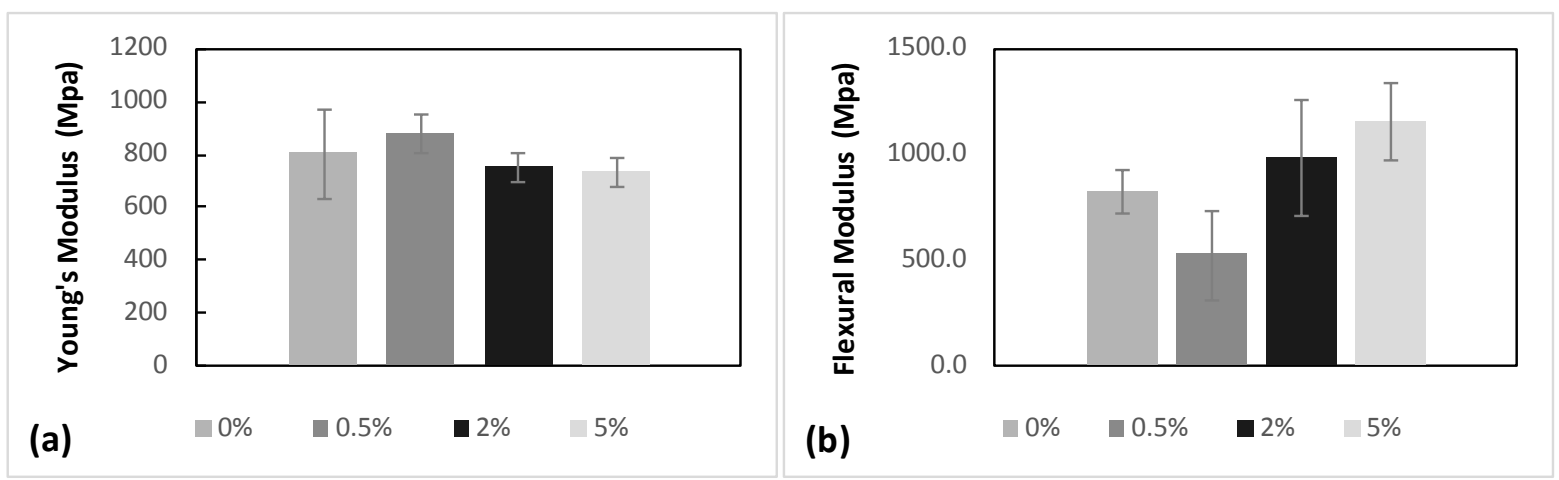

Figure 2. (a) Young's modulus and (b) Flexural modulus of epoxy resin reinforced with different amounts of PMMA nanofibers.

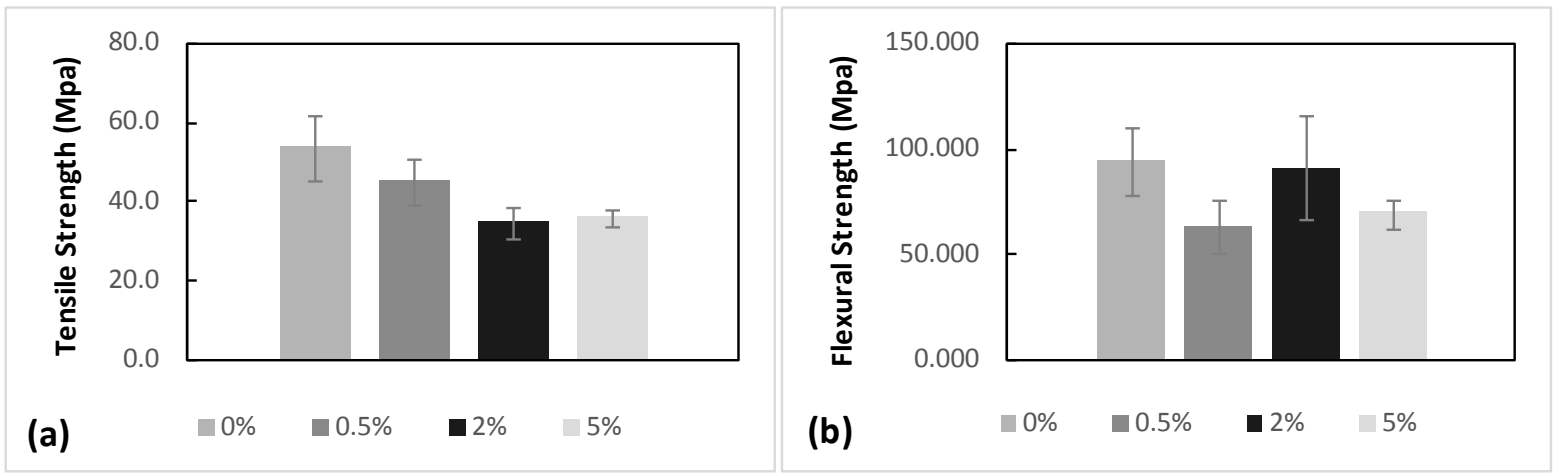

Figure 3. (a) Tensile strength and (b) Flexural Strength of epoxy resin reinforced with different amounts of PMMA nanofibers.

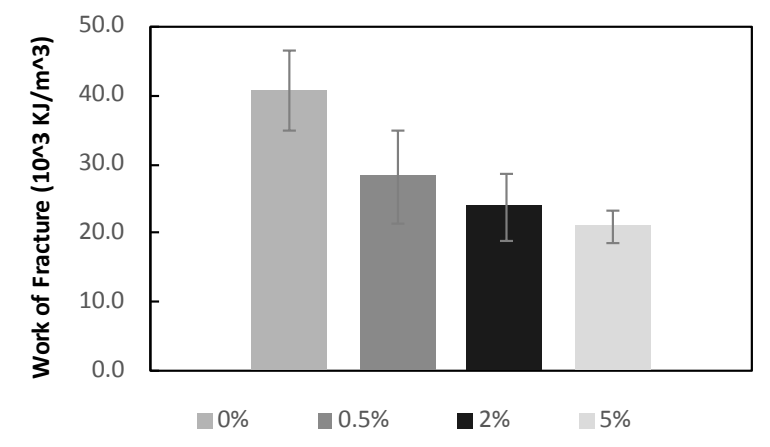

Figure 4. Work of fracture of epoxy resin reinforced with different amounts of PMMA nanofibers.

strength and WOF with increasing nanofiber content. Figure 5 and Figure 6 show SEM micrographs of 3-point bend test fracture surfaces for nanocomposite samples with $5 \mathrm{wt} \%$ PMMA at magnification of $2 \mathrm{k}$ and $20 \mathrm{k}$ respectively. Figure 5 shows presence of porosity throughout the fracture surface. It appears that there was air entrapment during mixing of the fibers with the resin, and the use of vacuum during curing was not sufficient to release the air. Furthermore, Figure 6 shows clean fiber-matrix interface in locations where fibers were pulled out during the test. This clean interface indicates poor fiber/matrix bonding. Also, an examination of the fracture surface indicates absence of fiber toughening behavior due to lack of long lengths of fiber pullout [16].

The results of this study are limited to the type of resin and nanofiber used, as fiber/matrix adhesion can be improved by using more compatible materials [10] [11]. Also, the use of functional coatings to enhance adhesion can enhance fiber/matrix adhesion and result in improved mechanical performance. For future work, we 


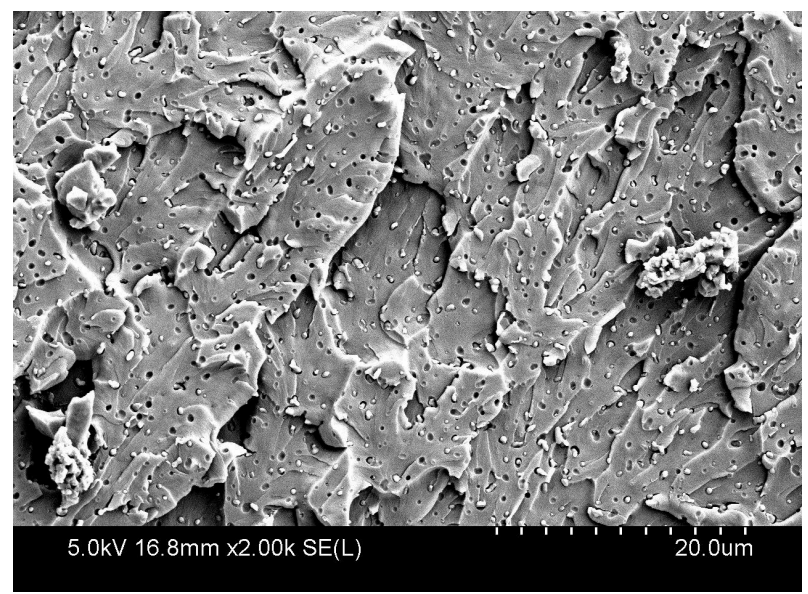

Figure 5. SEM micrograph of 3-point bend test fracture surface for sample with $5 \mathrm{wt} \%$ PMMA nanofibers at a magnification of $2 \mathrm{k}$.



Figure 6. SEM micrograph of 3-point bend test fracture surface for sample with $5 \mathrm{wt} \%$ PMMA nanofibers at a magnification of $20 \mathrm{k}$.

will study various types of coatings to improve fiber/matrix interface. We will also modify resin mix and processing method to eliminate air entrapment in the cured nanocomposites. This could be achieved by the addition of air release and wetting agents, in addition to applying vacuum for a longer period of time after every mixing step.

\section{Conclusion}

Effect of uncoated PMMA nanofiber content in epoxy nanocomposites was determined in this study. Results showed drop in tensile strength and WOF with the increase in PMMA nanofiber content. Young's modulus results showed no noticeable change in modulus after adding PMMA nanofibers. SEM micrographs of fracture surfaces showed presence of porosity and poor fiber/matrix bonding. In addition, SEM micrographs showed poor fiber toughening behaviour due to lack of long lengths of fiber pullout. This work shows the need to develop functional coatings for PMMA nanofibers for various matrices to improve mechanical behaviour of the nanocomposite.

\section{Acknowledgements}

The authors would like to thank Revolution Fibres Ltd. and Nuplex Industries Ltd. for providing materials for 
this project. The author would also like to thank Patrick Conor for his valuable assistance on the SEM.

\section{References}

[1] Alubaidy, A., Venkatakrishnan, K. and Tan, B. (2013) Nanofibers Reinforced Polymer Composite Microstructures. In: Maguire, R., Ed., Advances in Nanofibers, InTech, Croatia, 166.

[2] Huang, Z.-M., Zhang, Y.-Z., Kotaki, M. and Ramakrishna, S. (2003) A Review on Polymer Nanofibers by Electrospinning and Their Applications in Nanocomposites. Composite Science and Technology, 63, 2223-2252. http://dx.doi.org/10.1016/S0266-3538(03)00178-7

[3] Subbiah, T., Bhat, G.S., Tock, R.W., Parameswaran, S. and Ramkumar, S.S. (2005) Electrospinning of Nanofibers. Journal of Applied Polymer Science, 96, 557-569. http://dx.doi.org/10.1002/app.21481

[4] Reneker, D.H., Yarin, A.L., Zussman, E. and Xu, H. (2007) Electrospinning of Nanofibers from Polymer Solutions and Melts. Advances in Applied Mechanics, 41, 43-195. http://dx.doi.org/10.1016/S0065-2156(07)41002-X

[5] Bhardwaj, N. and Kundu, S.B. (2010) Electrospinning: A Fascinating Fiber Fabrication Technique. Biotechnology Advances, 28, 325-347. http://dx.doi.org/10.1016/j.biotechadv.2010.01.004

[6] Teo, W.-E., Inai, R. and Ramakrishna, S. (2011) Technological Advances in Electrospinning of Nanofibers. Science and Technology Advanced Materials, 12, 1-19. http://dx.doi.org/10.1088/1468-6996/12/1/013002

[7] Lozano, K. and Barrera, E.V. (2001) Nanofiber-Reinforced Thermoplastic Composites. I. Thermoanalytical and Mechanical Analyses. Journal of Applied Polymer Science, 79, 125-133. http://dx.doi.org/10.1002/1097-4628(20010103)79:1<125::AID-APP150>3.0.CO;2-D

[8] Rodriguez, A.J., Guzman, M.E., Lim, C.-S. and Minaie, B. (2011) Mechanical Properties of Carbon Nanofiber/Fiber-Reinforced Hierarchical Polymer Composites Manufactured with Multiscale-Reinforcement Fabrics. Carbon, 49, 937-948. http://dx.doi.org/10.1016/j.carbon.2010.10.057

[9] Li, B., Yuan, H. and Zhang, Y. (2013) Transparent PMMA-Based Nanocomposite Using Electrospun Graphene-Incorporated PA-6 Nanofibers as the Reinforcement. Composite Science and Technology, 89, 134-141. http://dx.doi.org/10.1016/j.compscitech.2013.09.022

[10] Jiang, S., Greiner, A. and Agarwal, S. (2013) Short Nylon-6 Nanofiber Reinforced Transparent and High Modulus Thermoplastic Polymeric Composites. Composites Science and Technology, 87, 164-169. http://dx.doi.org/10.1016/j.compscitech.2013.08.011

[11] Jiang, S., Duan, G., Schobel, J., Agrawal, S. and Greiner, A. (2013) Short Electrospun Polymeric Nanofibers Reinforced Polyimide Nanocomposites. Composites Science and Technology, 88, 57-61. http://dx.doi.org/10.1016/j.compscitech.2013.08.031

[12] Lin, S., Cai, Q., Ji, J., Sui, G., Yu, Y., Yang, X., Ma, Q., Wei, Y. and Deng, X. (2008) Electrospun Nanofiber Reinforced and Toughened Composites through in Situ Nano-Interface Formation. Composites Science and Technology, 68, 3322-3329. http://dx.doi.org/10.1016/j.compscitech.2008.08.033

[13] Vidotti, H.A., Manso, A.P., Leung, V., do Valle, A.L., Ko, F. and Carvalho, R.M. (2015) Flexural Properties of Experimental Nanofiber Reinforced Composite Are Affected by Resin Composition and Nanofiber/Resin Ration. Dental Materials, 31, 1132-1141. http://dx.doi.org/10.1016/j.dental.2015.06.018

[14] Yao, J., Li, G., Bastiaansen, C.W.M. and Peijs, T. (2015) High Performance Co-Polyimide Nanofiber Reinforced Composites. Polymer, 76, 46-51. http://dx.doi.org/10.1016/j.polymer.2015.08.054

[15] Ahmadi, M., Masoomi, M. and Safi, S. (2015) Mechanical Property Characterization of Carbon Nanofiber/Epoxy Nanocomposites Reinforced by GMA-Grafted UHMWPE Fibers. Composites Part B, 83, 43-49. http://dx.doi.org/10.1016/j.compositesb.2015.08.006

[16] Bansal, N.P. and Eldridge, J.I. (1999) Effects of Fiber/Matrix Interface and Its Composition on Mechanical Properties of Hi-Nicalon/Celsian Composites. NASA/TM-1999-209057, Proceedings of ICCM-12 Conference, Paris, 5-9 July $1999,147$. 